\title{
Orientations Toward Personnel Selection: Differential Reliance on Appearance and Personality
}

\author{
Mark Snyder, Ellen Berscheid, and Alana Matwychuk \\ University of Minnesota
}

\begin{abstract}
In two studies we examined the hypothesis that the psychological construct of self-monitoring would identify people who adopt distinctly different strategies in personnel selection. In both experiments, undergraduates examined information about the physical appearance and personalities of two applicants for a specific job and then decided which applicant should receive a job offer. In Study 1 information about the applicants' physical attractiveness and job-appropriate dispositions was varied. In Study 2 job appropriateness of the applicants' physical appearance and of their personalities were both varied. In each study, high self-monitoring individuals placed greater weight on information about physical appearance than did low self-monitoring individuals. By contrast, low self-monitoring individuals put greater weight on information about personal dispositions than did high selfmonitoring individuals. We discuss the implications for understanding personnel selection as well as for decision making in interpersonal contexts.
\end{abstract}

Some of the most important and consequential decisions in people's lives are made by other people. Who to befriend or avoid, marry or divorce, acquit or convict, hire or fire are all decisions about others with potentially significant consequences. A natural concern, therefore, is how these decisions are made. Recent research strongly suggests that people adopt systematically different approaches to gathering, weighing, and acting on information about other people when initiating personal relationships. At least one set of differing orientations may be identified with stable differences between individuals in their self-monitoring propensities (Glick, 1985; Omoto, DeBono, \& Snyder, 1987; Snyder, Berscheid, \& Glick, 1985). These investigations on the initiation of romantic relationships were guided by the psychological construct of self-monitoring (see Snyder, 1979, 1987).

High self-monitoring individuals typically strive to be the type of person called for by each situation in which they find themselves and thus are particularly sensitive and responsive to interpersonal and situational specifications of behavioral appropriateness; they use this information to monitor and control the images of self that they project to others in social situations. As investigations on the initiation of personal relationships indicate, high self-monitoring individuals also appear to carry this concern with their own public appearances to a concern with the images conveyed by people with whom they may be

This research and the preparation of this article were supported by National Science Foundation Grant BNS 82-07632 to Mark Snyder, by a grant-in-aid of research from the Graduate School of the University of Minnesota to Ellen Berscheid and Mark Snyder, and by a Social Sciences and Humanities Research Council of Canada Doctoral Fellowship to Alana Matwychuk. We thank Peter Glick for his helpful comments on this article.

Correspondence concerning this article should be addressed to Mark Snyder, Department of Psychology, University of Minnesota, 75 East River Road, Minneapolis, Minnesota 55455. associated. For example, when choosing whether to initiate a date, high self-monitoring individuals were particularly concerned with the physical appearance of potential dating partners (Snyder et al., 1985). In contrast, low self-monitoring individuals are not so concerned with tailoring their behavior to fit situational and interpersonal considerations. Rather, these people seem particularly concerned with behaving in ways that reflect consistently and accurately their own enduring attitudes, traits, and dispositions. In addition, they appear to carry this concern with their own personal dispositions over to a concern with the suitability of the personal dispositions possessed by people they select for a relationship partner. When initiating dating relationships, low self-monitoring individuals were particularly concerned with the personality attributes of potential dating partners (Snyder et al., 1985).

Dating situations, of course, elicit concerns about the images and impressions projected to one's public (Waller, 1937) and concerns about the attributes of the dating partner selected. Several studies indicate that both the potential relationship partner's physical attractiveness and personality characteristics are factors that college students report guide their personal date selections (Hudson \& Henze, 1969; Miller \& Rivenbark, 1970; Perrin, 1921; Tesser \& Brodie, 1971). Moreover, the finding that the physically attractive are more strongly preferred in the date selections of high self-monitoring individuals than the selections of low self-monitoring individuals is less startling when evidence concerning the perception of physically attractive people is examined. Not only may it be the case that our culture provides norms dictating that the physically attractive should be the preferred targets for romantic involvement (Berscheid \& Walster, 1974), but one may increase one's own prestige and the favorableness of the impression one makes on others by associating with a physically attractive person of the other sex. Sigall and Landy (1973), for example, showed that when a man appeared to have a physically attractive girlfriend, he elicited the most favorable overall impression from outside observers; when 
his girlfriend was physically unattractive, he was viewed the most negatively overall. When the man appeared to be unassociated with the woman, her attractiveness did not influence the impression he made. Further, the men themselves believed others would think more of them when they were associated with an attractive woman and that association with an unattractive woman would detract from the positivity of the impression they otherwise would have enjoyed. If it is true that the physically attractive are generally perceived to be the most appropriate partners for dating relationships, and if it is true that romantic association with the physically attractive enhances one's prestige and esteem from others, then high self-monitoring individuals should be more concerned than low self-monitoring individuals with the physical attractiveness of individuals they select for dates given that they are particularly concerned with projecting appropriate images to others in social situations.

It is not clear, however, whether these systematic differences in the manner in which individuals select relationship partners would extend to selections and decisions in other social contexts. It is not clear, for example, that these differences exist under circumstances in which the relationship is more restricted from public view, particularly situations in which the person selected will never be identified with the chooser or will never actually interact further with the chooser. In such contexts, would we still see differential responsiveness to considerations of personal dispositions and physical attractiveness when making decisions about people?

One way to address this question can be found in the general domain of issues that industrial and organizational psychologists in the personnel selection area have been addressing for over 70 years. One of their goals has been to determine the reliability and validity of hiring decisions and to discover the various variables that influence these choices (e.g., Arvey, 1979; Arvey \& Campion, 1982; Binet, 1911; Dipboye, 1982; Dunnette \& Borman, 1979; Wagner, 1949). Unfortunately, the popularity of the question is not reflected in the definitiveness of available answers. As Arvey and Campion (1982) have observed, research investigating the impact of systematic individual differences among decision makers on hiring decisions is lacking. Furthermore, recent reviews of the literature on employee selection also indicate that little is known about when and why initial impressions and subsequent personnel selection decisions will be influenced by particular applicant characteristics (e.g., Zedeck \& Cascio, 1984).

To the extent that self-monitoring is implicated more generally in differential responsiveness to considerations of personal dispositions and physical appearances when making decisions about people in other contexts, self-monitoring propensities may influence the activities of those who select job applicants. People high and low in self-monitoring may differ systematically in their notions about what applicant characteristics are pertinent to their hiring decisions. In addition, and perhaps as a function of these differences, they also may differ systematically in their weighing and use of different types of information available about applicants. Needless to say, job applicants rarely possess all of the desired characteristics and qualifications for a given job. Therefore, in selecting a candidate, some desired qualities may have to be forsaken for others considered even more desirable. Selecting a job applicant in situations in which candidates do not have all of the desired characteristics should most clearly reveal the priorities of the individual decision maker.

In the experiments reported here, we hypothesized that although all people may consider both the candidate's physical appearance and the favorability of her or his personal dispositions, low self-monitoring individuals should be more concerned with a prospective candidate's personal dispositions, whereas high self-monitoring individuals should be more concerned with an applicant's physical appearance. To examine these hypotheses, we conducted two studies.

\section{Study 1}

After identifying people relatively high or low in self-monitoring, we brought them into an experimental situation and asked them to decide which applicant should receive a job offer for a particular position. Each decision maker examined information about the job and two candidates, one of whom possessed personal dispositions suitable to the job but was unattractive in appearance and the other of whom was physically attractive but had personal dispositions unsuitable for the job.

\section{Method}

Participants. Thirty-eight undergraduates (18 women and 20 men) enrolled in an introductory psychology course at the University of Minnesota participated for course credit. Scores on the 18-item version of the Self-Monitoring Scale (Snyder \& Gangestad, 1986), collected earlier in the academic quarter, were available for all participants. There were 19 high (scores $\geq 11$ ) and 19 low (scores $\leq 10$ ) self-monitoring participants. The 18-item version of the Self-Monitoring Scale consists of the 18 items of the original measure that most validly assess the general selfmonitoring factor. (For information on the psychometric properties of the 18-item measure, as well as a comprehensive discussion of issues concerning the assessment of self-monitoring and the relative validities of alternative measures of self-monitoring, see Snyder \& Gangestad, 1986.)

Procedure. Participants were scheduled for individual sessions. When each one arrived, a female experimenter (unaware of the participant's self-monitoring classification) explained that she was studying informational aspects of personnel selection and that the participant would decide, on the basis of a limited amount of information, which one of two applicants should be hired for a specific job. She went on to claim that the study was being conducted in conjunction with a personnel office and that the applicants were two of several people who had applied for the position. Therefore, she maintained, the participant's hiring decision, even though it would not determine whether any specific applicant was hired, would have an impact on the future selection policies of the personnel office. The experimenter then handed the participant a job description and two files.

Stimulus materials. In all instances, the one-paragraph job description indicated that the position was that of laboratory technician at the University of Minnesota hospital. The laboratory technician's primary duties were identified as administering tests to patients, conducting analyses on specimens obtained from patients, and writing reports. Each file contained a page of information about one of the two female applicants to be considered for this position. On that page were a small $(5 \times 4 \mathrm{~cm})$ yearbook-type photograph of the applicant, her first name, social security number, file number, and test scores from three scales of the (fictitious) Minnesota Personality Inventory.

One file contained information about "Beth." Beth's photograph revealed that she was relatively unattractive in appearance. However, the 
Table 1 Applicant Choices in Study 1

\begin{tabular}{ccc}
\hline & \multicolumn{2}{c}{$\begin{array}{c}\text { Individual's self- } \\
\text { monitoring } \\
\text { category }\end{array}$} \\
\cline { 2 - 4 } Type of applicant & Low & High \\
\hline Attractive appearance/unsuitable personality & .16 & .53 \\
Suitable personality/unattractive appearance & .84 & .47 \\
\hline
\end{tabular}

Note. Entries are the proportion of participants in each self-monitoring category who chose each type of applicant for the lab technician position; $n=19$ for each self-monitoring category.

personality characteristics attributed to Beth were highly suited to the position (she was described as being sociable, as possessing a high level of organizational ability, and as being average in leadership ability). The other file contained information about "Liz." Her photograph revealed that she was physically attractive, and the personality summary indicated that Liz possessed a personality less suited to the position than Beth's (she was described as being relatively unsociable, as possessing a low level of organizational ability, and as being slightly above average in leadership ability).

Both the applicants' photographs and the personality traits attributed to them were chosen on the basis of pretesting. Prior to the experiment, 21 University of Minnesota undergraduates rated the applicants' photographs and personality summaries. All of the pretest judges' ratings were made on a 7-point scale. The pretest judges (a) viewed Liz as being significantly more attractive $(M=5.52)$ than Beth $(M=2.95), t(20)=$ $9.76, p<.001$; (b) judged Beth's personality attributes as being significantly more appropriate for the lab technician position $(M=5.42)$ than Liz's $(M=4.71)$, one-tailed $t(20)=3.25, p<.01$; and (c) perceived the two applicants as being equivalent in terms of the appropriateness of their physical appearances for the lab technician position, $t(20)=$ $0.55, n s$.

Dependent measures. After examining the job description and the information about the two applicants, the participant indicated which applicant should be hired for the lab technician position and was debriefed by the experimenter.

\section{Results}

Job applicant choice. The proportion of low and high selfmonitoring individuals who chose each applicant is reported in Table 1. Individual contrasts (see Johnson, 1976, regarding onetailed $z$ tests for proportions) revealed a significant Self-Monitoring $\times$ Type of Applicant interaction composed of the two predicted simple effects: High self-monitoring individuals $(p=$ .53) were more likely than low self-monitoring individuals ( $p=$ .16) to choose the attractive applicant with the relatively unsuitable personality, and low self-monitoring individuals $(p=.84)$ were more likely than high self-monitoring individuals $(p=.47)$ to choose the applicant with the suitable personality but unattractive appearance, $z=2.40, p<.01 .^{1}$

\section{Discussion}

Study 1 revealed that people do in fact differ systematically in their approaches to personnel selection. When choosing the one candidate they would hire, high self-monitoring individuals were willing to forego suitable personal dispositions for a pleas- ing physical appearance; low self-monitoring individuals were willing to select a physically unattractive candidate in order to choose someone who possessed suitable personal dispositions for the position. These results indicate that in the domain of personnel selection, high self-monitoring individuals place greater weight on considerations of physical appearances, whereas low self-monitoring individuals put greater weight on information about personal dispositions.

We designed the procedure in this study to be optimal for discovering differences in the extent to which people used information about physical attractiveness and information about personal dispositions. The applicants' photographs were chosen to ensure that although one applicant was physically more attractive than the other, the overall physical appearance of the two applicants was viewed as equally appropriate to the job under consideration, as our preexperiment ratings confirmed.

In naturalistic situations, however, job candidates not only differ in their levels of physical attractiveness, as they did in Study 1 , but they also differ in the appropriateness of their looks for the particular jobs they seek. People clearly possess definite images of the physical appearance appropriate for members of different occupations (e.g., Cantor \& Mischel, 1979; Goffman, 1959; Neff, 1977; Weber \& Crocker, 1983). A job-appropriate appearance need not necessarily be, although it may be, a physically attractive appearance. For example, conceptions of the kind of appearance appropriate to a librarian or to a religious worker are less likely to contain the feature good looking than are those of a receptionist or an airline stewardess.

Accordingly, from both a theoretical and an experimental standpoint, there are two ways to produce variation in the physical appearances of job candidates. Appearance can be varied, as in Study 1, in terms of levels of physical attractiveness. Appearance can also be varied in terms of the extent to which the applicants' appearances fit the stereotypic image of people ideally suited for the job. ${ }^{2}$ There are a variety of reasons, grounded in self-monitoring theory and research, suggesting that high self-monitoring individuals should be particularly sensitive and responsive to this latter criterion: whether the applicants' appearances fit the stereotypic conception of the appropriate appearance for members of the occupation under consideration.

First, this hypothesis seems to follow from the core tenets of self-monitoring theory (Snyder, 1987). According to theoretical analyses of self-monitoring, people differ systematically in the extent to which they characteristically guide their behavioral choices on the basis of information about situational and interpersonal specifications of behavioral appropriateness (high selfmonitoring) and on the basis of information about their relevant inner attributes (low self-monitoring). Perhaps these differing orientations may be reflected in the selection of applicants for jobs. High self-monitoring individuals, who are particularly concerned with projecting situationally appropriate images of self to others in social situations, may carry this concern

\footnotetext{
'No overall effect for participants' gender was found, $z=0.727, n s$.

${ }^{2}$ As we noted in the introduction, attractiveness and appropriateness may go hand in hand in the dating context, where an attractive date may be regarded as an appropriate one. However, as reported in Study 1, the attractive and unattractive candidates were not perceived as possessing differentially job-appropriate appearances.
} 
with their own public appearances over to a concern with the job appropriateness of the appearance conveyed by people they choose for particular jobs. Moreover, if it is true that in the personnel selection context, a situationally appropriate appearance need not necesarily be a physically attractive appearance, it seems likely that whether job candidates' appearances fit the stereotypic image of the ideal candidate for a job rather than their physical attractiveness should take precedence in the hiring decisions of high self-monitoring individuals.

There is some evidence relevant to this line of reasoning. High self-monitoring individuals, for example, are highly aware of the messages conveyed by clothing and personal effects, and they choose these items according to their strategic value in controlling the images they project in social situations (e.g., Davis \& Lennon, 1985). Also, the wardrobes of high self-monitoring men contain more different items of clothing in more different styles than the wardrobes possessed by low self-monitoring men who, relatively speaking, have homogenous and internally coherent wardrobes (Zaidman \& Snyder, 1983). Thus, when making personnel selection decisions, high self-monitoring individuals may be more likely than low self-monitoring individuals to choose an applicant based on the extent to which the applicant's clothing, personal effects, and other self-presentational aspects of appearance project the appropriate image for the job under consideration.

Further in this regard, high self-monitoring individuals may even consider a job-appropriate appearance as an asset that will contribute to successful job performance, reasoning (either explicitly or implicitly) that a job holder who looks like holders of that job should look will be better able to enact the role behaviors associated with the job. Generalizing from previous studies of self-monitoring and friendship, which have revealed a high self-monitoring preference for activity "specialists" in high selfmonitoring individuals' social lives (e.g., Snyder, Gangestad, \& Simpson, 1983), perhaps these individuals assume that appropriate-appearing candidates are in some sense activity or performance specialists for the jobs they seek.

In a similar vein, high self-monitoring individuals may be particularly concerned with the job appropriateness of applicants' appearances and may prefer appropriate-looking candidates to attractive ones because they assume that appropriateappearing candidates are more willing and able to do what is necessary to fit into the job environment. After all, they appear already to have done so, at least to the extent that they have used clothing, grooming, cosmetics, and accessories to tailor their appearances to stereotyped conceptions of the looks appropriate to the job under consideration. In this sense, the strategic presentation of a job-appropriate appearance may be more informative than sheer physical attractiveness, because physical attractiveness itself is largely not a controllable aspect of appearance.

Finally, one could argue that high self-monitoring individuals are more likely to prefer appropriate-looking candidates because years of concern with the appropriateness of their own appearances have resulted in habitual self-evaluations of the appropriateness of their own appearances. Perhaps this habitual pattern may even result in a chronically accessible construct for appropriate appearances (Higgins \& King, 1981). Research charting the links between self-monitoring and person percep- tion in fact suggests that high self-monitoring individuals have richer, better articulated, and more informative images of others who are prototypic examples in a wide variety of behavioral domains than do low self-monitoring individuals (Snyder \& Cantor, 1980).

Singly and together, these interrelated aspects of self-monitoring propensities suggest that high self-monitoring individuals may be particularly concerned with the extent to which job applicants' appearances fit the stereotypic conception of the appropriate appearance for members of the occupation under consideration. To discern whether persons high or low in selfmonitoring are differentially sensitive to this appropriateness criterion of appearance in job selection, we conducted a second study.

\section{Study 2}

In this study we presented people with the choice between hiring either (a) a job candidate who possessed personal dispositions suitable to the job but who had a relatively inappropriate appearance for the job under consideration or (b) a job candidate who possessed a physical appearance well suited to the particular job but who had relatively unsuitable personal dispositions. To make this test of the individual decision maker's priorities as stringent as possible, we tried to separate considerations of the applicants' level of physical attractiveness from considerations of the appropriateness of the applicants' looks for the job. Thus, we asked participants to make a hiring recommendation for each of two positions. For one position, the applicant who possessed the more appropriate appearance for the job was clearly the less physically attractive candidate. For the other job, the applicant who had the more job-appropriate appearance was also the more physically attractive alternative. ${ }^{3}$

We sought to determine whether high self-monitoring individuals, for the reasons outlined earlier, would carry over their concern with their own situationally appropriate images to a concern with the job appropriateness of the appearance conveyed by people they choose for particular jobs. If so, we would predict that they would choose to hire the candidate whose appearance was the most appropriate for the job under consideration regardless of their physical attractiveness. Similarly, we sought to determine whether low self-monitoring individuals, who are particularly concerned with behaving in ways that reflect consistently and accurately their own enduring attitudes, values, and dispositions, would carry this concern with their own personal dispositions over to a focus on the suitability of the personal dispositions possessed by people they select for jobs regardless of the applicants' appearance. If so, we would predict that they would select the job applicant whose personal dispositions were the most suitable for the job.

\footnotetext{
${ }^{3}$ Note that this design is an incomplete factorial, because it does not include choices involving either an appropriate appearance/suitable personality candidate or an inappropriate appearance/unsuitable personality candidate. Such choices would not be theoretically informative because there is little plausible reason why participants, whether high or low in self-monitoring, would not select the former or why they would select the latter.
} 


\section{Method}

Participants. Twenty-two individuals ( 9 women and 13 men) enrolled in an introductory psychology course at the University of Minnesota participated in this investigation for course credit. Scores on the 18item version of the Self-Monitoring Scale (Snyder \& Gangestad, 1986), collected previously, were available for all participants. Twelve students with high scores $(\geq 11)$ and 10 students with low scores $(\leq 10)$ participated in individually scheduled sessions.

Procedure. When each participant arrived, a female experimenter (unaware of participants' self-monitoring classification) explained that she was examining informational aspects of personnel selection and that the participant would make hiring decisions based on limited amounts of information. The experimenter further explained that for each of the two jobs, the participant would decide which of two candidates should be hired. To help establish realism, she identified the applicants as people who had actually applied for the jobs. The experimenter also claimed that because she was working with a personnel office, the participant's decision would influence the office's future policies but not the hiring of these applicants. She then handed the participant a job description and files containing information about two applicants for the jobs of salesclerk and camp counselor, with the order of presentation randomized across participants.

Stimulus materials. For each position, the participant examined a one-paragraph job description and a one-page description of each applicant containing a $20 \times 13-\mathrm{cm}$ color photograph of the applicant, his or her first name, social security number, file number, and test scores on three personality scales of the (fictitious) Minnesota Personality Inventory. For each position, one applicant had personality traits highly suited to the position and a relatively job-inappropriate appearance, whereas the other applicant possessed a physical appearance highly appropriate for the job and relatively unsuitable personality traits. Additionally, for one job, the applicant with the more job-appropriate appearance was clearly the less physically attractive; for the other job, the more physically attractive applicant also possessed the more job-appropriate appearance.

The camp counselor position was described as working with children aged 10 to 15 years at the (fictitious) University of Minnesota Outdoor Program and supervising activities such as canoeing, camping, and backpacking. One camp counselor file contained information about "Robert." Robert's photograph revealed that he was physically attractive but had a job-inappropriate appearance (he wore a dark pin-striped suit with matching tie and shirt). However, the personality characteristics attributed to Robert were highly suited to the job (he was described as being sociable, empathic, and decisive). The other file contained information about "David." David's photograph revealed that he was relatively unattractive but looked like a camp counselor (he was neatly but casually attired in a corduroy sports jacket and had a beard); his personality test scores indicated he had a less suitable personality for the job than Robert (he was described as being decisive but relatively low in sociability and empathy).

For the salesclerk position, the job description indicated that the primary duties were assisting clients in a sophisticated women's clothing store and handling payment transactions. One saleclerk applicant file contained information about "Liz." Liz clearly possessed a highly appropriate physical appearance for the salesclerk position (she wore a black sweater with pearls and black pin-striped trousers) and she was very attractive; however, she also had unsuitable personality characteristics for the position (she was described as being relatively low in sociability, organizational ability, and leadership). The other salesclerk applicant, "Beth," possessed suitable personality characteristics for the salesclerk position (she was said to be relatively high in sociability and organizational ability but low in leadership); she, however, had a relatively job-inappropriate physical appearance (she wore a dowdy blouse and her hair was neat but unfashionable) and was relatively unattractive.
The applicants' photographs and the personality traits attributed to them were chosen on the basis of pretesting. Prior to the experiment, 14 University of Minnesota undergraduates rated each of the applicant's personality summary and photograph. All ratings were made on a 7 point scale. The judges viewed (a) David's appearance as being significantly more appropriate for the camp counselor position $(M=5.50)$ than Robert's $(M=3.17), t(11)=3.50, p<.01$; (b) David $(M=3.42)$ as being much less attractive than Robert $(M=4.83), t(11)=3.26, p<$ .01 ; and (c) Robert's personality as being significantly more appropriate to the camp counselor position $(M=6.00)$ than David's $(M=4.57)$, $t(13)=3.98, p<.01$. Similarly, the judges (a) rated Liz's appearance as being much more appropriate to the salesclerk position $(M=5.67)$ than Beth's $(M=3.17), t(11)=5.72, p<.001$; (b) viewed $\mathrm{Liz}$ as being much more attractive $(M=5.08)$ than $\operatorname{Beth}(M=3.08), t(11)=4.06, p<.01$; and (c) viewed Beth's personality as being significantly more appropriate to the salesclerk position $(M=5.86)$ than Liz's $(M=4.36), t(13)=$ $6.57, p<.001$.

Dependent measures. Immediately after examining the job description and the information about the applicants, the participant indicated which of the two applicants should be hired. The participant then answered the question "Which type of information contained in the files was most important to you in making your choice of a job applicant to recommend for the job?" and was debriefed by the experimenter.

\section{Results}

Choice of job applicant. The proportions of low and high self-monitoring individuals who chose each job applicant are reported in Table 2, with the data presented separately for the salesclerk and camp counselor position. As indicated by a significant one-tailed $z$ test for proportions (Johnson, 1976), when choosing an applicant for the salesclerk position, low self-monitoring individuals $(p=.90)$ were more likely than high selfmonitoring individuals $(p=.58)$ to choose the applicant with the suitable personality but inappropriate appearance; high self-monitoring individuals $(p=.42)$ were more likely than low self-monitoring individuals $(p=.10)$ to choose the applicant with the more appropriate appearance but relatively unsuitable personality, $z=1.66, p<.05$.

That high self-monitoring individuals were more likely to choose the appropriate-looking applicant for the salesclerk position should be seen in the context of the fact that this applicant's appearance was both appropriate and attractive. It is the data for the camp counselor position that permits the clearest test of the hypothesis that it is the job appropriateness rather than the physical attractiveness of a candidate's appearance that is important to high self-monitoring individuals. In this instance, to choose the appropriate-looking candidate meant to countermand the preference value of physical attractiveness. Individual contrasts, performed on the camp counselor data, revealed a Self-Monitoring $\times$ Type of Applicant interaction composed of the two predicted simple effects. Also, the camp counselor data seemed to be stronger than the salesclerk data. As indicated by a significant $z$ test for proportions, when choosing a camp counselor applicant, low self-monitoring individuals $(p=.90)$ were more likely than high self-monitoring individuals $(p=.50)$ to choose the applicant with the suitable personality but inappropriate appearance; high self-monitoring individuals $(p=.50)$ were more likely than low self-monitoring individuals $(p=.10)$ to choose the applicant with the more appropriate 
appearance but relatively unsuitable personality, one-tailed $z=$ $2.01, p<.025 .^{4}$

Reasons for choosing a job applicant. We also examined participants' oral reports about which type of information had been most important in their hiring decisions for each job position. These responses are presented in Table $3 .{ }^{5}$ In their reports for the salesclerk position, $67 \%$ of the low self-monitoring individuals but only $27 \%$ of the high self-monitoring individuals claimed that the personality information was the most important factor in their hiring decision. In sharp contrast, $73 \%$ of the high self-monitoring individuals and only $33 \%$ of the low selfmonitoring individuals cited information in the photographs as most important. This difference between high and low selfmonitoring individuals was significant, one-tailed $z=1.76, p<$ .05 . Similarly, in their self-reported claims about which type of information had been most important for their decision of whom to hire for the camp counselor position, a substantial majority of the low self-monitoring individuals $(90 \%)$ claimed that internal attribute information was the most important factor in their choice of an applicant; in contrast, a definite majority of high self-monitoring individuals (58\%) cited the information in the photographs as being the most important. Again, individual contrasts revealed that this difference between high and low selfmonitoring individuals is a highly significant one, one-tailed $z=2.35, p<.01 .^{6}$ The parallels between the stated reasons and the actual choices of applicants suggest that these self-reports were accurate indications of participants' decision-making behavior.

\section{Discussion}

Study 2 provided further evidence of a relation between selfmonitoring and personnel selection strategies. When choosing the one candidate they would hire, low self-monitoring individuals were willing to forego a job-appropriate appearance for suitable personality traits. High self-monitoring individuals instead were willing to accept a candidate with unsuitable personal dispositions in order to gain someone who possessed a job-appropriate appearance. Moreover, it appears that for high

Table 2

Applicant Choices in Study 2

\begin{tabular}{|c|c|c|}
\hline \multirow[b]{2}{*}{ Job position } & \multicolumn{2}{|c|}{$\begin{array}{l}\text { Individual's } \\
\text { self- } \\
\text { monitoring } \\
\text { category }\end{array}$} \\
\hline & Low & High \\
\hline \multicolumn{3}{|l|}{ Camp counselor } \\
\hline Appropriate appearance/unsuitable personality & .10 & .50 \\
\hline Suitable personality/inappropriate appearance & .90 & .50 \\
\hline \multicolumn{3}{|l|}{ Salesclerk } \\
\hline Appropriate appearance/unsuitable personality & .10 & .42 \\
\hline Suitable personality/inappropriate appearance & .90 & .58 \\
\hline
\end{tabular}

Note. Entries are the proportion of participants in each self-monitoring category who chose each type of applicant for each job position; $n \mathrm{~s}=$ 12 for high self-monitoring individuals and 10 for low self-monitoring individuals.
Table 3

Reasons for Choosing an Applicant in Study 2

\begin{tabular}{ccc}
\hline & \multicolumn{1}{c}{$\begin{array}{c}\text { Individual's self- } \\
\text { monitoring category }\end{array}$} \\
\cline { 2 - 3 } Job position & Low & High \\
\hline Camp counselor & & \\
$\quad$ Photographs & .10 & .58 \\
$\quad$ Personal attributes & .90 & .42 \\
Salesclerk & .33 & .73 \\
$\quad$ Photographs & .67 & .27 \\
\hline Personal attributes & & \\
\hline
\end{tabular}

Note. Entries are the proportion of participants in each self-monitoring category who offered each type of stated reason for choosing the applicant. For the camp counselor data, $n s=12$ for high self-monitoring individuals and 10 for low self-monitoring individuals. For the salesclerk data, $n s=11$ for high self-monitoring individuals and 9 for low selfmonitoring individuals.

self-monitoring individuals, whether an applicant's appearance fit the stereotypic image of people ideally suited for the job took precedence over physical attractiveness. Recall, for example, that for the camp counselor job, high self-monitoring decision makers preferred the candidate who looked like a camp counselor even though he was far from handsome and even though he possessed an inappropriate personality. In sum, high selfmonitors were particularly likely to select an applicant who looked the part for the job, whereas low self-monitors were more inclined to choose an applicant who was the part for the job.

\section{General Discussion}

We have proposed that in personnel selection, decision makers differ systematically in their notions about what characteristics of applicants are pertinent to their hiring choices. Some of these differences, our studies have demonstrated, are associated with self-monitoring propensities. High self-monitoring individuals placed greater weight on physical appearance when choosing between job applicants. In contrast, low self-monitoring individuals placed greater emphasis on personality dispositions when deciding between candidates. ${ }^{7}$ Further, these links

\footnotetext{
${ }^{4}$ No overall effects for gender were found: for the salesclerk data, $z=$ $0.44, n s$; for the camp counselor data, $z=0.13, n s$.

5 Two participants, one high and one low in self-monitoring, reported that the personal attribute information and the photograph were equally important in determining their choice for the salesclerk position. Their responses were excluded from the self-report analysis of the salesclerk data.

${ }^{6}$ No overall effects for gender were found: for the salesclerk data, $z=$ $0.17, n s$; for the camp counselor data, $z=0.25, n s$.

${ }^{7}$ We also examined the possible differences that could arise from classifying participants using the 18-item version of the Self-Monitoring Scale versus the original 25 -item measure by reclassifying each of the studies' participants with the participants' self-monitoring classifications based on a median-split of the 25 -item scale scores. For each of the participants in the two studies, the participant's self-monitoring classification obtained using the 25 -item classification system was identical to the self-monitoring classification obtained using the 18-item classification system.
} 
between self-monitoring and personnel selection priorities were evident regardless of whether we examined appearance using information about the applicants' physical attractiveness (Study 1) or information about the job appropriateness of the applicants' physical appearance (Study 2). However, our findings also underscore the importance of differentiating between these two aspects of appearance. Although job-appropriate and physically attractive appearances may go hand in hand, they often do not. When they do not, as Study 2 revealed, it is the job appropriateness rather than the physical attractiveness of a candidate's appearance that is of paramount concern to decision makers concerned with such matters.

Of what consequence are the differences revealed here in how people make personnel decisions? Reviews of the literature on personnel selection indicate that little is known about when and why particular applicant characteristics have an impact on selection outcomes (e.g., Arvey \& Campion, 1982; Dipboye, 1982; Zedeck \& Cascio, 1984). For instance, some studies suggest that physically attractive job candidates are preferred over physically unattractive ones (e.g., Cann, Siegfried, \& Pearce, 1981; Carlson, 1967; Dipboye, Arvey, \& Terpstra, 1977; Dipboye, Fromkin, Wiback, 1975), but other studies do not (e.g., Cash, Gillen, \& Burns, 1977). Most of these studies have overlooked possible systematic differences between decision makers in their personal orientation toward personnel selection as well as the job appropriateness of the candidates' appearances, an appearance-based factor that may be orthogonal to attractiveness. Our results suggest that it is possible to identify categories of people who will be swayed by the appearances of those they evaluate for jobs (high self-monitoring individuals) and people who will be moved by relevant information about the personal dispositions of job candidates (low self-monitoring individuals).

Thus far in our research, we have considered the role of information about physical appearance and personality traits in personnel selection. However, generalizing beyond our results, we may expect high self-monitoring individuals to be impressed by other appearance-based characteristics of job candidates (e.g., demeanor, mannerisms, gender, age) and low self-monitoring individuals to be persuaded by other dispositional characteristics (e.g., evidence of experience, training or aptitude test scores).

\footnotetext{
We also examined the possible independent contributions of independent factors that may exist within the overall measure of self-monitoring by correlating each of the dependent measures of the two studies (choice in Study 1, choice and reason in Study 2) with participants' scores on each of the three factors (Acting, Extraversion, Other-Directedness) suggested by Briggs, Cheek, and Buss (1980). We also calculated the correlation between each dependent measure and participants' scores on the original 25 -item Self-Monitoring Scale. For each of the dependent variables in the two studies, the correlation between each measure and both the participants' scores on each of the three component factors and the participants' 25 -item scale scores were not significantly different from the correlation between each measure and participants' overall scores on the 18-item self-monitoring measure, all ts $n s$, following computational procedures described by Cohen and Cohen (1983). For further discussions of matters associated with analyses by factorial components of the self-monitoring measure, and the implications of such analyses, see Snyder and Gangestad (1986).
}

In addition, there may be long-term consequences of the personal orientations that are brought to bear in personnel selection decisions. It has been repeatedly demonstrated that people's first impressions of others affect their subsequent interactions, often with self-fulfilling consequences (e.g., Snyder, Tanke, \& Berscheid, 1977). Once in the job setting, considerations similar to those involved in the selection situation may be invoked when evaluations are made about who should be awarded raises or promotions or who should obtain the most desired project or work assignment. When the evaluations are made by high self-monitoring individuals, matters of appearance or style may come into play. When these same judgments are made by low self-monitoring individuals, however, considerations of performance on the job may be particularly important. The cumulative effect may be that job holders ultimately come to confirm and reinforce the decision-making considerations that first granted them entry to their jobs.

For now, these implications must remain conjecture. On the other hand, they do suggest the usefulness of the approach taken in our studies. That is, understanding how decisions are made in work environments may depend not only on considerations of applicant or job incumbent characteristics, but also on considerations of the differential approaches by which employers gather, weigh, and act on information about employees. Such decisions may be the product of an interaction between the decision maker's orientation toward personnel selection and the characteristics of the potential (or incumbent) employee.

Our findings should be viewed in the context of other evidence of systematically different orientations toward making decisions about other people. We indicated at the outset that studies of dating relationships suggest that low self-monitoring individuals are particularly concerned with the personality attributes of potential dating partners, whereas high self-monitoring individuals are particularly concerned with the physical attractiveness of their dating partners. The studies reported here, using the personnel selection context, indicate that people do not adopt differing decision-making orientations only with respect to people they themselves may be associated with. Rather, these systematic orientations exist even when the person selected will never be identified with the decision maker or will never actually interact further with the decision maker, attesting to the generality of these differing orientations. Perhaps more important, this research goes one step further by demonstrating that these orientations lead people to go beyond physical attractiveness and socially desirable attributes and to focus differentially on situationally appropriate aspects of appearance and situationally appropriate aspects of personality.

\section{References}

Arvey, R. D. (1979). Unfair discrimination in the employment interview: Legal and psychological aspects. Psychological Bulletin, 86, 736-765.

Arvey, R. D., \& Campion, J. E. (1982). The employment interview: A summary and review of recent research. Personnel Psychology, 35, $281-322$.

Berscheid, E., \& Walster, E. (1974). Physical attractiveness. Advances in Experimental Social Psychology, 7, 157-215.

Binet, A. (1911). Nouvelles recherches sur la mesure du niveau intellec- 
tuel chez les enfants d'école [New research on a measure of intelligence in school children]. L'Année Psychologique, 17, 145-201.

Briggs, S. R., Cheek, J. M., \& Buss, A. H. (1980). An analysis of the Self-Monitoring Scale. Journal of Personality and Social Psychology, 38, 679-686.

Cann, E., Siegfried, W. D., \& Pearce, L. (1981). Forced attention to specific applicant qualifications: Impact on physical attractiveness and sex of applicant biases. Personnel Psychology, 34, 65-76.

Cantor, N., \& Mischel, W. (1979). Prototypes and person perception. Advances in Experimental Social Psychology, 12, 3-52.

Carlson, R. E. (1967). Selection interview decisions: The relative influence of appearance and factual written information on an interviewer's final rating. Journal of Applied Psychology, 51, 461-468.

Cash, T. F., Gillen, B., \& Burns, D. S. (1977). Sexism and "Beautyism" in personnel consultant decision making. Journal of Applied Psychology, 62, 301-310.

Cohen, J., \& Cohen, P. (1983). Applied multiple regression/correlation analysis for the behavioral sciences. Hillsdale, NJ: Erlbaum.

Davis, L. D., \& Lennon, S. J. (1985). Self-monitoring, fashion opinion leadership, and attitudes towards clothing. In M. Solomon (Ed.), Psychology of fashion (pp. 177-182). Lexington, MA: Heath.

Dipboye, R. L. (1982). Self-fulfilling prophecies in the selection-recruitment interview. Academy of Management Review, 7, 579-586.

Dipboye, R. L., Arvey, R. D., \& Terpstra, D. E. (1977). Sex and physical attractiveness of raters and applicants as determinants of résumé evaluations. Journal of Applied Psychology, 62, 288-294.

Dipboye, R. L., Fromkin, H. L., \& Wiback, K. (1975). Relative importance of applicant sex, attractiveness, and scholastic standing in evaluation of job applicant résumés. Journal of Applied Psychology, 60 39-43.

Dunnette, M. D., \& Borman, W. C. (1979). Personnel selection and classification systems. Annual Review of Psychology. 30, 477-526.

Glick, P. (1985). Orientations towards relationships: Choosing a situation in which to begin a relationship. Journal of Experimental Social Psychology, 21, 544-562.

Goffman, E. (1959). The presentation of self in everyday life. New York: Doubleday.

Higgins, E. T., \& King, G. A. (1981). Accessibility of social constructs: Information-processing consequences of individual and contextual variability. In N. Cantor \& J. F. Kihlstrom (Eds.), Personality, cognition. and social interaction (pp. 69-121). Hillsdale, NJ: Erlbaum.

Hudson, J. W., \& Henze, L. F. (1969). Campus values in mate selection: A replication. Journal of Marriage and the Family, 31, 772-775.

Johnson, R. (1976). Elementary Statistics (2nd ed.). North Scituate, MA: Duxbury Press.

Miller, H. L., \& Rivenbark, W. H., III. (1970). Sexual differences in physical attractiveness as a determinant of heterosexual likings. Psychological Reports, 27, 701-702.
Neff, W. S. (1977). Work and human behavior. Chicago: Aldine.

Omoto, A. M., DeBono, K. G., \& Snyder, M. (1987). Personality and relationship initiation: Advertising in the personals. Unpublished manuscript, University of Minnesota, Minneapolis.

Perrin, F. A. C. (1921). Physical attractiveness and repulsiveness. Journal of Experimental Psychology, 4, 203-217.

Sigall, H., \& Landy, D. (1973). Radiating beauty: Effects of having a physically attractive partner on person perception. Journal of Personality and Social Psychology, 28, 218-224.

Snyder, M. (1979). Self-monitoring processes. Advances in Experimental Social Psychology, 12, 85-128.

Snyder, M. (1987). Public appearances/private realities: The psychology of self-monitoring. New York: Freeman.

Snyder, M., Berscheid, E., \& Glick, P. (1985). Focusing on the exterior and the interior: Two investigations of the initiation of personal relationships. Journal of Personality and Social Psychology, 48, 14271439.

Snyder, M., \& Cantor, N. (1980). Thinking about ourselves and others: Self-monitoring and social knowledge. Journal of Personality and Social Psychology, 39, 222-234.

Snyder, M., \& Gangestad, S. (1986). On the nature of self-monitoring: Matters of assessment, matters of validity. Journal of Personality and Social Psychology, 51, 125-139.

Snyder, M., Gangestad, S., \& Simpson, J. A. (1983). Choosing friends as activity partners: The role of self-monitoring. Journal of Personatity and Social Psychology, 45, 1061-1072.

Snyder, M., Tanke, E. D., \& Berscheid, E. (1977). Social perception and interpersonal behavior: On the self-fulfilling nature of social stereotypes. Journal of Personality and Social Psychology, 35, 656-666.

Tesser, A., \& Brodie, M. (1971). A note on the evaluation of a "computer date." Psychonomic Science, 23, 300.

Wagner, R. (1949). The employment interview: A critical summary. Personnel Psychology, 2, 17-46.

Waller, W. (1937). The rating and dating complex. American Sociological Review, 2, 727-737.

Weber, R., \& Crocker, J. (1983). Cognitive processes in the revision of stereotypic beliefs. Journal of Personality and Social Psychology, 45, 961-977.

Zaidman, B., \& Snyder, M. (1983). [Choice of clothing]. Unpublished raw data.

Zedeck, S., \& Cascio, W. F. (1984). Psychological issues in personnel decisions. Annual Review of Psychology, 35, 461-518.

Received August 20, 1987

Revision received November 17, 1987

Accepted January 15, 1988 